\title{
Formation of Smectic Orientational Order in an Ionic Thermotropic Liquid-Crystalline Side-Chain Polymer
}

\author{
Seiji UjIIE and Kazuyoshi IImURA \\ Department of Chemistry, Faculty of Science, Science University of Tokyo, \\ Kagurazaka, Shinjuku-ku, Tokyo 162, Japan
}

(Received June 29, 1992)

\begin{abstract}
A nonionic thermotropic liquid-crystalline polymer [NI-LCP] and its ionic family [LCPEI-M-Br] were synthesized. Their liquid-crystalline properties were compared, and the effects of poly(ammonium salt) backbones in LCPEI-M-Br for liquid-crystalline properties were studied. Nonionic NI-LCP exhibited a nematic phase with a schlieren texture. However, ionic LCPEI-M-Br formed smectic phases with fan textures by an aggregation of poly(ammonium salt) backbones. Ionic LCPEI-M-Br showed the enhanced thermal stability in comparison with nonionic NI-LCP. Ionic LCPEI-M-Br formed an ammonium bilayer consisting of ionic and nonionic sublayers. LCPEI-M-Br also formed spontaneously a homeotropic structure in the smectic phase by orientational adsorption of ammonium ions.

KEY WORDS Ionic Smectic Polymer / Poly(ammonium salt) Backbone /

Comb-Like / Thermal Property / Orientational Behavior /Oriented

Overgrowth /
\end{abstract}

Many low molecular weight (LMWLCs) and polymeric (PLCs) liquid crystals have been synthesized up to the present. LMWLCs and PLCs usually form either thermotropic or lyotropic mesophases. Orientational orders in thermotropic mesophases of nonionic partially rigid molecules arise from interactions between rigid anisotropic groups (mesogens). ${ }^{1,2}$ An aggregation of polar head groups in amphiphilic molecules also leads to the formation of fluid anisotropy in lyotropic and thermotropic mesophases. ${ }^{3-6}$ In general, several alkylammonium and alkylpyridinium salts are known as thermotropic liquid crystals, and in this case, the ammonium ions act effectively in producing the mesomorphic order. Recently, we reported that the ion complex type low molecular weight and polymeric liquid-crystalline compounds exhibit the enhanced thermal stability and epitaxial orientational behavior by the effect of ammonium ions. ${ }^{7}$

We are convinced that the introduction of ammonium ions into nonionic comb-like PLCs can lead to the formation of stable liquid-crystalline systems encompassing both mesomorphic orientational ordering formed by mesogens and fluid anisotropy arising from the aggregation of ionic groups. ${ }^{8}$ We synthesized an ionic thermotropic liquid-crystalline side-chain polymer (LCPEI-M-Br) consisting of a poly(ammonium salt) backbone and mesogenic side groups with flexible spacers. A nonionic family (NI-LCP) of LCPEI-M-Br was also prepared, and the liquid-crystalline properties of NI-LCP and LCPEI-M-Br were compared. In this paper, we report the effects of the poly(ammonium salt) backbone for the formation of the liquid-crystalline phase. The orientational behavior of LCPEI-M-Br is also discussed. 


\section{RESULTS AND DISCUSSION}

Effect of Poly(ammonium salt) Backbone on Liquid-Crystalline Behavior

The structure of the nonionic liquid-crystalline side-chain polymer (NI-LCP) consists of a poly(amine) chain and mesogenic side groups as shown in Figure 1. Nonionic NILCP exhibited only an enantiotropically nematic phase with a schlieren texture (see Figure 3). The nematic orientational order of NI-LCP forms by anisotropy arising from interactions between the mesogenic groups. In this case, a schematic illustration of the nematic ordering is shown in Figure 5a.

On the other hand, the structure of the ionic liquid-crystalline side-chain polymer (LCPEI$\mathrm{M}-\mathrm{Br}$ ) is shown in Figure 2. Ionic LCPEI$\mathrm{M}-\mathrm{Br}$ exhibited enantiotropically smectic A and unidentified smectic (smectic $\mathrm{X}$ ) phases in which nonionic NI-LCP did not form. LCPEI-M-Br formed a fan-shaped texture in the smectic A phase, as shown in Figure 4 and also showed a similar fan-shaped textrure on cooling in the smectic X phase.

The smectic orientational order in LCPEI$\mathrm{M}-\mathrm{Br}$ forms by the aggregation of poly(ammonium salt) backbones, which consist of poly(ethyleneiminium) and bromide ion, in addition to anisotropy arising from interactions between mesogenic groups. This is schematically illustrated in Figure $5 b$. In Figure 5b, the counterions (bromide ions), as shown with open circles, will be displaced above and below the plane of the figure to minimize repulsive interactions. In Figures 6, 9 , and 11 , also, the counterions are illustrated in the same way as Figure 5b. The aggregation of poly(ammonium salt) backbones in smectic LCPEI-M-Br is caused by Coulomb's force which is absent in nematic NI-LCP, and acts effectively, forming and stabilizing the smectic layer structure. In this case, the poly(ammonium salt) backbone in LCPEI-M-Br acts as a smectogenic species. This corresponds to the fact that, in general, amphiphilic

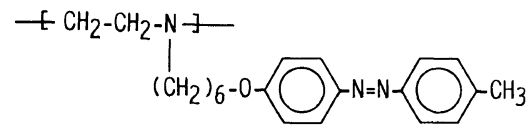

Figure 1. Structure of nonionic liquid-crystalline sidechain polymer (NI-LCP).

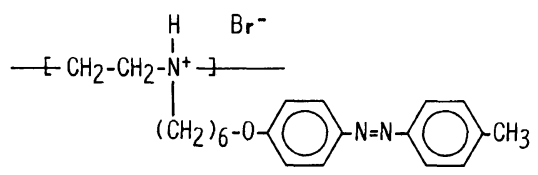

Figure 2. Structure of ionic liquid-crystalline side-chain polymer (LCPEI-M-Br).

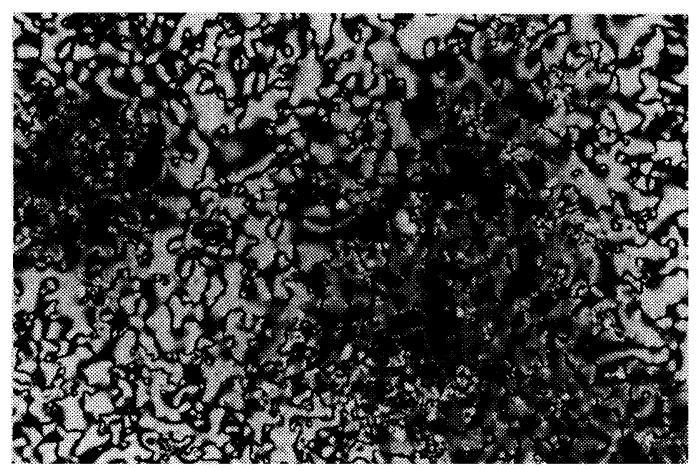

Figure 3. Schlieren texture observed in nematic phase of NI-LCP.

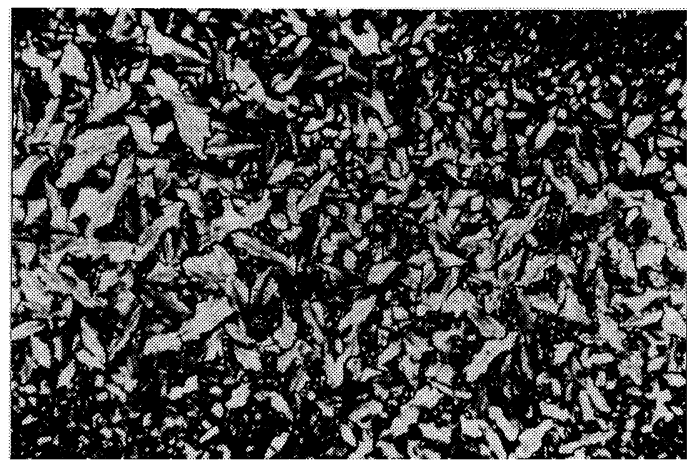

Figure 4. Fan texture observed in smectic $A$ phase of LCPEI-M-Br.

molecules such as alkylammonium salts exhibit smectic phases through the effect of Coulomb's force.

In general, alkylammonium salts exhibit higher melting points than their nonionic 


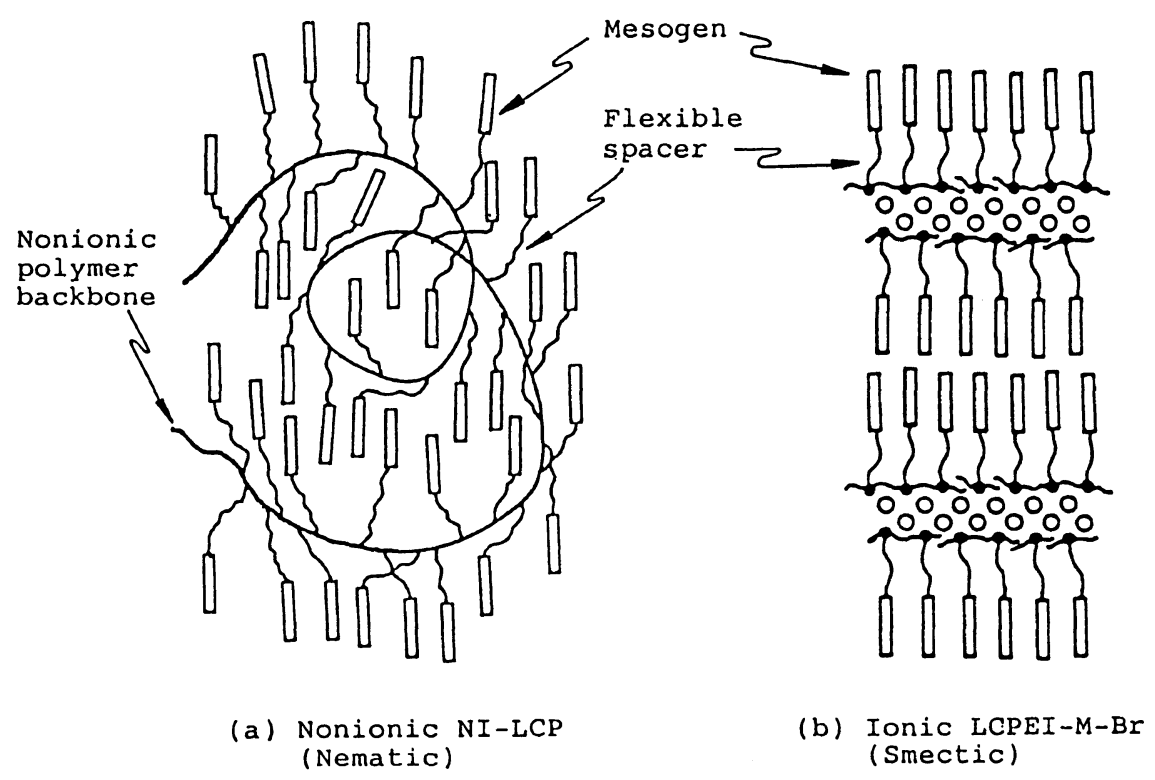

Figure 5. Schematic illustrations of molecular orientations: (a), nematic orientation of NI-LCP; (b), smectic orientation of LCPEI-M-Br; (O), ammonium ion; $(\mathrm{O})$, counterion. In LCPEI-M-Br, the ionic sublayer forms through Coulomb's force. The counterions will be displaced above and below the plane of Figure $5 \mathrm{~b}$ to minimize repulsive interactions.

Table 1. Phase transition temperatures of ionic LCPEI-M-Br and nonionic NI-LCP

\begin{tabular}{lcc}
\hline Sample & $\overline{M_{\mathrm{n}}}$ & Phase transition temperatures $/{ }^{\circ} \mathrm{C}$ \\
\hline LCPEI-M-Br & 6000 & G 37.1 SmX 80 SmA 146 I \\
NI-LCP & 5000 & G 10 N 87.2 I
\end{tabular}

a G, glassy state; SmX, unidentified smectic phase; SmA, smectic A phase; N, nematic phase; I, isotropic phase.

components because ammonium salts form an ionic aggregation by Coulomb's force which is absent between nonionic compounds. For instance, ethylenediammonium chloride $\left(\mathrm{mp}>300^{\circ} \mathrm{C}\right)$, which is made of ethylenediamine and hydrochloride, exhibits a higher melting point than ethylenediamine $(\mathrm{mp}$ $\left.8.5^{\circ} \mathrm{C}\right)$. In the case of LCPEI-M-Br, the aggregation of poly(ammonium salt) backbones also enhances the thermal stability of the smectic phase. A smectic-isotropic phase transition temperature $\left(T_{\mathrm{i}}\right)$ of ionic LCPEI$\mathrm{M}-\mathrm{Br}$ is higher by $58.8^{\circ} \mathrm{C}$ when comparaed to
$T_{\mathrm{i}}$ of nonionic NI-LCP (see Table I). Furthermore, LCPEI-M-Br exhibits a higher glass transition temperature than NI-LCP because the restriction of the thermal motion of poly(ammonium salt) backbones is due to the ionic aggregation.

\section{Spontaneous Formation of Homeotropic Struc- ture}

LCPEI-M-Br formed spontaneously a homeotropic structure by annealing in the sandwich cell without surface treatment. Also, the homeotropic structure formed in epitaxy when the upper glass plate of the sandwich cell was removed. However, NI-LCP did not form spontaneously a homeotropic structure.

In general, surfactants such as alkylammonium halides are known to be effective as a perpendicular alignment-treatment agent. ${ }^{9}$ Liquid-crystalline systems containing a small amount of amphiphilic materials are aligned by the orientational adsorption of the polar head groups of the amphiphilic molecules. ${ }^{10,11}$ 


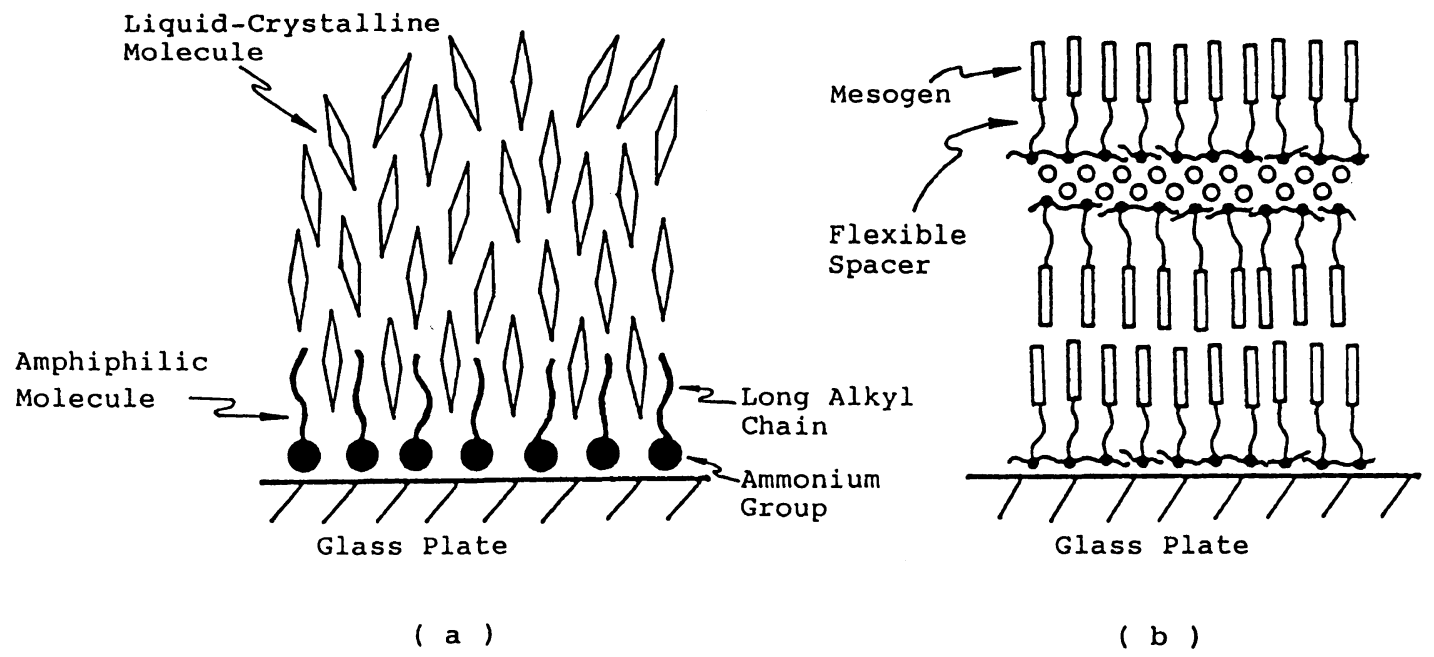

Figure 6. Schematic molecular orientations: (a), formation of homeotropic alignment in liquid-crystalline systems containing surfactant; (b), spontaneous formation of hometropic alignment in LCPEI-M-Br. ${ }^{14}$

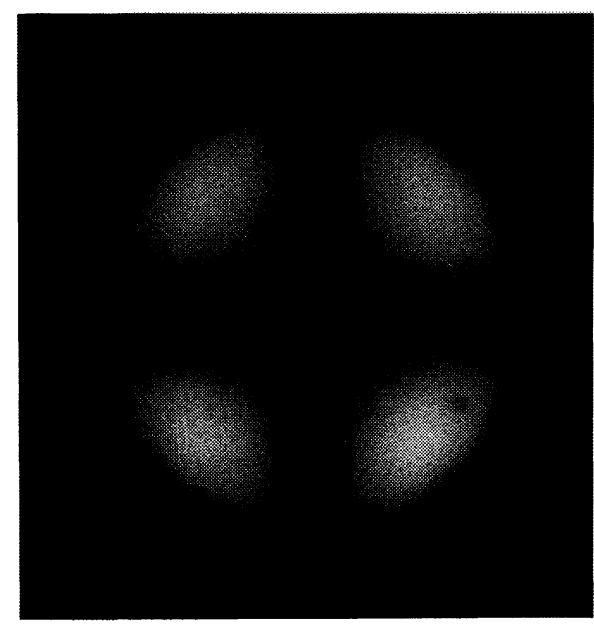

(a)

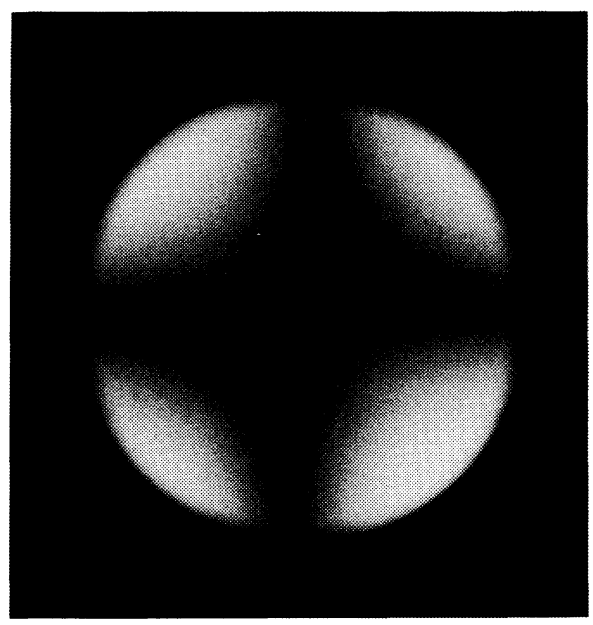

(b)

Figure 7. Conoscopic figures observed for homeotropically oriented sample of LCPEI-M-Br: (a), optical uniaxial conoscopic figure observed in smectic A phase; (b), optical biaxial conoscopic figure observed in smectic X phase.

In this case, a model for the homeotropic structures formed by amphiphilic molecules is schematically illustrated in Figure 6a. The liquid-crystalline molecules are aligned along the direction of the long alkyl chain of the amphiphilic molecule.

LCPEI-M-Br having the poly(ammonium salt) backbone can act as a perpendicular alignment agent. The poly(ammonium salt) backbone adsorbs on the glass surface, and mesogenic side groups are aligned perpendicularly. Subsequently, the homeotropic structue is organized, forming the smectic A layer structure by both the aggregation of poly- 
(ammonium salt) backbones and the arrangement of mesogenic side groups, as shown in Figure $6 \mathrm{~b}$. Thus, the epitaxially oriented overgrowth is produced in LCPEI-M-Br.

In the smectic A phase, an optically uniaxial conoscopic figure was observed for the homeotropic structure, as shown in Figure 7a. However, an optically biaxial oriented structure formed on cooling in the smectic $\mathrm{X}$ phase, and the conoscopic figure characteristic of an optically biaxial state was observed as shown in Figure $7 b .^{12,13}$

\section{Orientational Structures}

The smectic layer structure of LCPEI-M-Br was studied by $\mathrm{X}$-ray measurement and conoscopic observation. The stretched sample with the smectic A ordering of LCPEI-M-Br exhibited sharp Bragg spots at small angles on the equator and wide angle diffuse crescents located on the meridian perpendicular to the position of the small angle Bragg spots, as shown in Figure 8. The diffuse wide angle reflections are characteristic of the smectic A orientational order. The category of the smectic phase of LCPEI-M-Br was also characterized by conoscopic observation of the homeotropically oriented sample. As indicated in Figure 7a, LCPEI-M-Br exhibits an optically uniaxial conoscopic figure characteristic of the smectic A state.

The smectic A layer spacing of LCPEI-M-Br was $4.9 \mathrm{~nm}$ and longer by $0.7 \mathrm{~nm}$ than twice the length of the mesogenic side group $(2.1 \mathrm{~nm})$ estimated with a Stuart type space-filling model. This difference of $0.7 \mathrm{~nm}$ is related to an ionic sublayer formed by the aggregation of poly(ammonium salt) backbones. A pos-

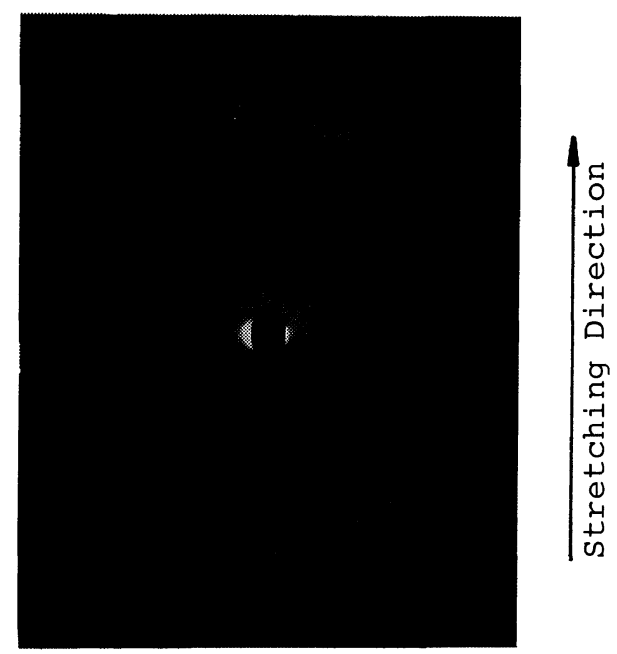

Figure 8. X-Ray differaction pattern for smectic A structure of LCPEI-M-Br.

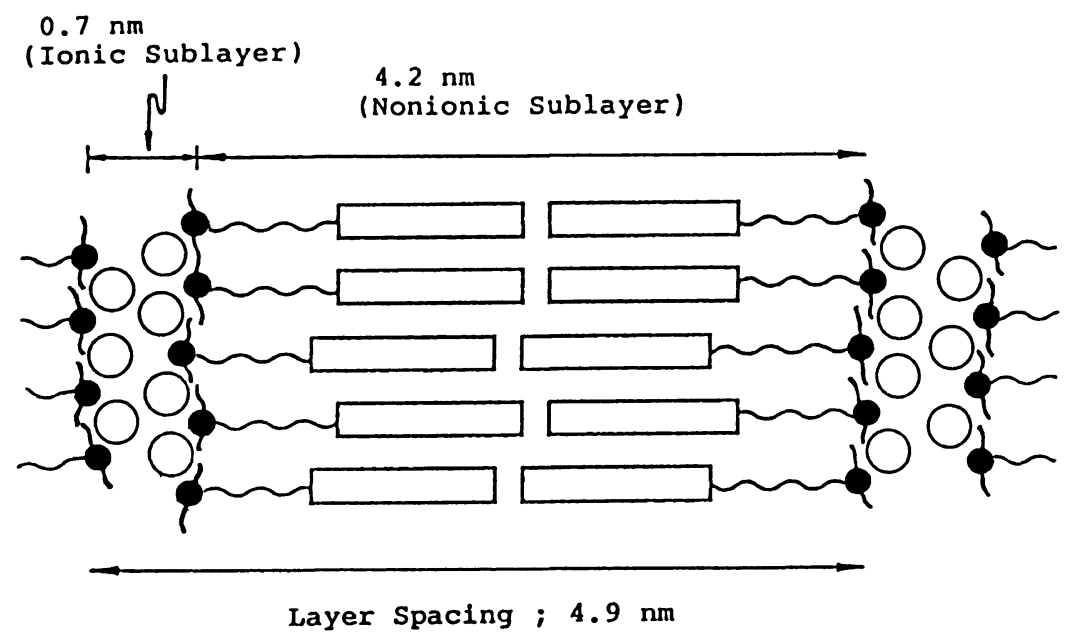

Figure 9. Possible packing model for smectic A layer structure of LCPEI-M-Br: (O), ammonium ion; (O), counterion ${ }^{14} ;(\square)$, mesogenic group. 
sible model for the smectic A ordering of LCPEI-M-Br is schematically illustrated in Figure 9. In this case, the smectic layer consists of ionic and nonionic sublayers and is similar to smectic structures formed by amphiphiles such as alkylammoniums or alkylpyridiniums.

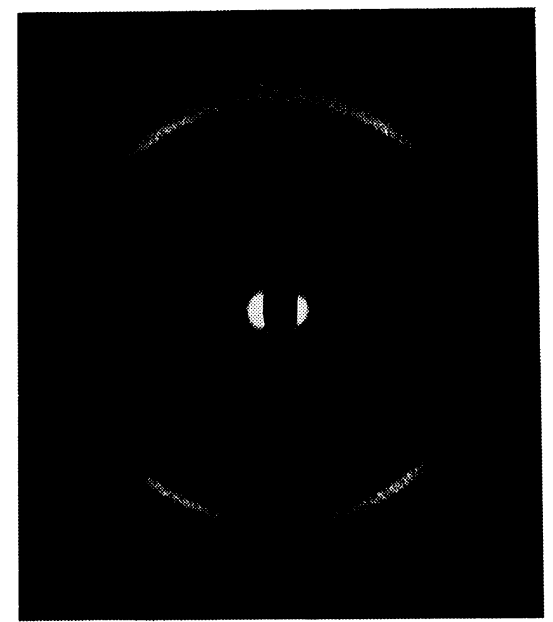

Figure 10. X-Ray diffraction pattern for smectic $\mathrm{X}$ structure of LCPEI-M-Br.
In LCPEI-M-Br, the formation of the ionic sublayer acts effectively in forming and stabilizing the smectic layer structure.

In the X-ray diffraction of the smectic $\mathrm{X}$ phase, LCPEI-M-Br shows the sharp Bragg spots at small angles on the equator and four reflections in the wide angle region, as shown in Figure 10. The four wide angle reflections demonstrate that a tilted ordering forms in the smectic $X$ phase. This corresponds to the fact that the smectic X ordering in LCPEI-M$\mathrm{Br}$ is optically biaxial (see Figure $7 \mathrm{~b}$ ). In the smectic A-X phase transition, LCPEI-M-Br exhibited a transition enthalpy of $1.1 \mathrm{~kJ} \mathrm{~mol}^{-1}$ characteristic of the first order phase transition. In this case, the smectic $X$ phase is a higher ordered-tilted state than a smectic $\mathrm{C}$ ordering because the transition of smectic $A$ to $C$ phases is the second order phase transition.

The smectic $X$ layer spacing $(4.2 \mathrm{~nm})$ is shorter than the smectic A layer spacing $(4.9 \mathrm{~nm})$ because the mesogenic side groups of LCPEI-M-Br form a tilted layer packing.

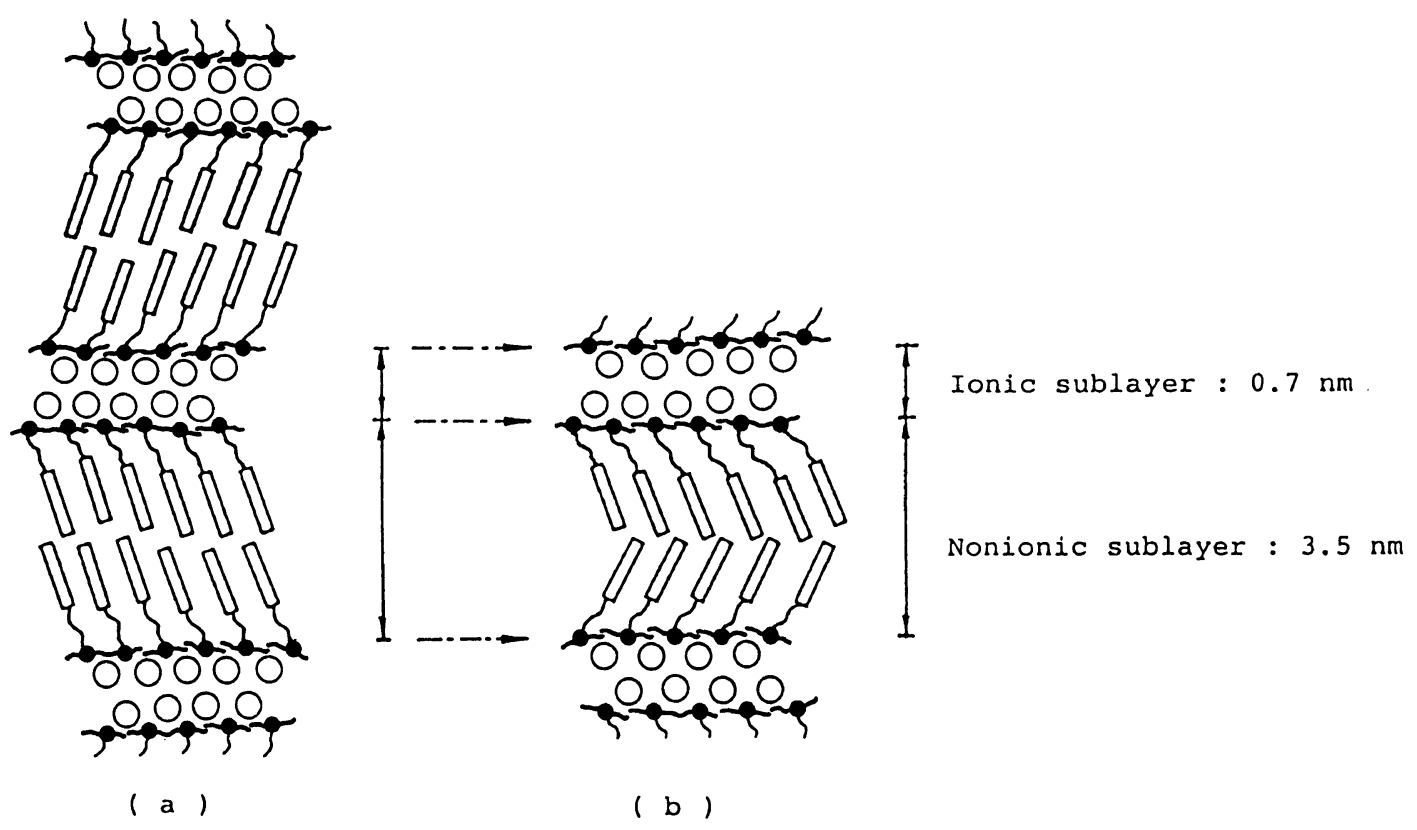

Figure 11. Possible packing models for smectic X layer structure of LCPEI-M-Br: Two packing models of both (a) and (b) are proposed for the smectic X phase: $(\bigcirc)$, ammonium ion; (O), counterion ${ }^{14} ;(\square)$, mesogenic group. 
The tile angle of the smectic $X$ phase was determined to be $31^{\circ}$ from both the smectic layer spacing and the splitting angle of reflections in the wide angle region. Possible packing models for the smectic $\mathrm{X}$ phase are schematically illustrated in Figures 11a and $11 \mathrm{~b}$. In the smectic $X$ phase, the coexistence of two types of packing models proposed in Figures $11 \mathrm{a}$ and $11 \mathrm{~b}$ is considered. The smectic X layer structure consists of an ionic sublayer (about $0.7 \mathrm{~nm}$ ) and a nonionic tilted layer arrangement (about $3.5 \mathrm{~nm}$ ) formed by the mesogenic side groups. It is expected that the mesogenic side groups of LCPEI-M-Br form a long range order in the smectic $\mathrm{X}$ layer.

\section{CONCLUSIONS}

The introduction of ammonium ions into the nonionic-nematic polymer leads to the formation of a smectic state having enhanced thermal stability. In the ionic liquid-crystalline side-chain polymer, the aggregation of ammonium structural units produces the smectic phase and enhances the thermal stability. The smectic layer consists of an ionic part formed by poly(ammonium salt) backbones and a nonionic arrangement part of the mesogenic side groups. The orientational adsorption of poly(ammonium salt) backbones promotes the epitaxially oriented overgrowth of the ionic liquid-crystalline side-chain polymer.

\section{EXPERIMENTAL}

\section{Characterization of Polymers}

Molecular weight of the polymers was determined with a Toso HLC 802UR gel permeation chromatograph (GPC) calibrated with standard polystyrenes. The phase transitions were measured with a Mettler TA3000 system (TC 10-DSC 20) and an Olympus polarizing microscope $\mathrm{BH}-2$ equipped with a Mettler FP52 hot stage apparatus with a Mettler FP5 temperature controller. X-ray diffraction was measured with a Rigaku X-ray
Rad 2B system using Ni-filtered $\mathrm{Cu} K_{\alpha}$ radiation.

\section{Synthesis}

Synthesis of 4'-Hydroxy-4-methylazobenzene. 4-Methylaniline (4 g, $37.4 \mathrm{mmol}$ ) was dissolved in hydrochloric acid $\left(12 \mathrm{moll}^{-1}, 30 \mathrm{ml}\right)$, and the solution was cooled below $5^{\circ} \mathrm{C}$. For the diazotation, a small amount of sodium nitrite was added at a temperature below $5^{\circ} \mathrm{C}$. To the cooled solution, a mixture of sodium hydroxide solution $(37.4 \mathrm{mmol})$ with phenol (37.4 mmol) was added. The reaction mixture was stirred for $1 \mathrm{~h}$ about $5^{\circ} \mathrm{C}$ and after the reaction was acidified with conc. hydrochloric acid. The precipitate was isolated by filtration and dried. Yield, 93\%.

Synthesis of 6-bromo-1-((4-((4-methylphenyl) azo)phenyl)oxy)hexane. 4'-Hydroxy-4-methylazobenzene $(4 \mathrm{~g}, 18.6 \mathrm{mmol})$ was dissolved in acetone $(100 \mathrm{ml})$, and potassium carbonate and 1,6-dibromohexane $(23 \mathrm{~g}, 93 \mathrm{mmol})$ were added. The reaction mixture was refluxed for $100 \mathrm{~h}$. The precipitated potassium bromide was filtered off, and the filtrate was evaporated under reduced pressure. Chloroform $(200 \mathrm{ml})$ was added to the crude product, and the chloroform solution was extracted ten times with water and evaporated. The product was recrystallized from the ethanol solution. Yield $60 \% .{ }^{1} \mathrm{H} \quad \mathrm{NMR} \quad\left(\mathrm{CDCl}_{3}\right): 1.5(\mathrm{~m}, 4 \mathrm{H}$, $\left.-\mathrm{O}-\mathrm{CH}_{2}-\mathrm{CH}_{2}-\mathrm{CH}_{2}-\mathrm{CH}_{2}-\right), 1.9(\mathrm{~m}, 4 \mathrm{H}$, $\left.-\mathrm{O}-\mathrm{CH}_{2}-\mathrm{CH}_{2}-\mathrm{CH}_{2} \mathrm{CH}_{2}-\mathrm{CH}_{2}-\right), 2.3(\mathrm{~s}, 3 \mathrm{H}$, $\left.-\mathrm{CH}_{3}\right), 3.4\left(\mathrm{t}, 2 \mathrm{H},-\mathrm{CH}_{2}-\mathrm{Br}\right), 4.0(\mathrm{t}, 2 \mathrm{H}$, \left.$-{\mathrm{O}-\mathrm{CH}_{2}}_{2}\right), 6.95$ (d, 2H, $\left.\underline{\mathrm{Ar}}\right), 7.25$ (d, 2H, Ar), 7.85 (m, 4H, Ar).

Synthesis of Ionic Liquid-Crystalline Polymer (LCPEI-M-Br). Poly[N-(6-((4-)(4-methylphenyl)azo)phenyl)oxy)hexyl)ethyleneiminium bromide] was prepared by addition reaction of polyethyleneimine with 6-bromo-1((4-(4-methylphenyl)azo)phenyl)oxy)hexane.

Polyethyleneimine $(0.1 \mathrm{~g})$ and 6-bromo-1((4-((4-methylphenyl)azo)phenyl)oxy)hexane $(0.87 \mathrm{~g}, 2.32 \mathrm{mmol})$ were dissolved in a mixed solution of tetrahydrofuran $(30 \mathrm{ml})$ and aceto- 
nitrile $(30 \mathrm{ml})$. The reaction mixture was refluxed for $300 \mathrm{~h}$. After the reaction, the reaction mixture was evaporated. The crude product was dissolved in tetrahydrofuran $(10 \mathrm{ml})$, and the ionic polymer was reprecipitated by adding hexane. Yield $70 \%$. ${ }^{1} \mathrm{H}$ NMR $\left(\mathrm{CDCl}_{3}\right): 1.5$ (br s, 4H, $-\mathrm{O}-\mathrm{CH}_{2}-\mathrm{CH}_{2}-\mathrm{CH}_{2}-$ $\mathrm{CH}_{2}-\mathrm{CH}_{2}-$ ), 1.8 (br s, $4 \mathrm{H},-\mathrm{O}-\mathrm{CH}_{2}-\overline{\mathrm{CH}}_{2}-$ $\left.\left(\mathrm{CH}_{2}\right)_{2}-\mathrm{CH}_{2}-\right), 2.4\left(\mathrm{~s}, 3 \mathrm{H},-\mathrm{CH}_{3}\right), 3.2(\mathrm{br} \mathrm{s}, 6 \mathrm{H}$, $\left.-\underline{\mathrm{CH}}_{2}-\mathrm{N}^{+}-\underline{\mathrm{CH}}_{2}-\right), 4.0\left(\mathrm{~s}, 2 \mathrm{H},-\mathrm{O}-\underline{\mathrm{CH}}_{2}-\right), 7.0$ $\mathrm{CH}_{2}-$

(s, 2H, Ar), 7.25 (s, 2H, Ar), 7.85 (d, 4H, Ar).

Synthesis of Nonionic Liquid-Crystalline Polymer (NI-LCP). Polyethyleneimine $(0.1 \mathrm{~g})$ and 6-bromo-1-((4-((4-methylphenyl)azo)phenyl)oxy)hexane $(0.87 \mathrm{~g}, 2.32 \mathrm{mmol})$ were dissolved in a mixed solution of tetrahydrofuran $(30 \mathrm{ml})$ and acetonitrile $(30 \mathrm{ml})$. To the reaction mixture, potassium carbonate was added, and the reaction mixture was refluxed for $300 \mathrm{~h}$. After the reaction, the reaction mixture was filtered off, and the filtrate was evaporated. The crude product was dissolved in tetrahydrofuran $(10 \mathrm{ml})$, and the nonionic polymer was reprecipitated by adding hexane. Yield $80 \%$. ${ }^{1} \mathrm{H}$ NMR $\left(\mathrm{CDCl}_{3}\right): 1.4(\mathrm{br} \mathrm{s}, 4 \mathrm{H}$, $-\mathrm{O}-\mathrm{CH}_{2}-\mathrm{CH}_{2}-\mathrm{CH}_{2}-\mathrm{CH}_{2}-$ ), 1.8 (br s, 4H, $\left.-\mathrm{O}-\mathrm{CH}_{2}-\mathrm{CH}_{2}-\left(\mathrm{CH}_{2}\right)_{2}-\mathrm{CH}_{2}-\mathrm{CH}_{2}-\right), 2.2$ (s, $\left.2 \mathrm{H},-\mathrm{N}-\mathrm{CH}_{2}-\mathrm{CH}_{2}-\mathrm{CH}_{2}-\right), 2.3\left(\mathrm{~s}, 3 \mathrm{H},-\mathrm{CH}_{3}\right)$, $2.8\left(\right.$ br s, $\left.4 \mathrm{H},-\mathrm{N}-\underline{\mathrm{CH}}_{2}-\underline{\mathrm{CH}}_{2}-\mathrm{N}-\right), 3.9(\mathrm{br} \mathrm{s}, 2 \mathrm{H}$, $\left.-\mathrm{O}-\underline{\mathrm{CH}}_{2}-\right), 6.7$ (d, 2H, $\left.\underline{\mathrm{Ar}}\right), 7.1$ (d, 2H, $\left.\underline{\mathrm{Ar}}\right)$, $7.6(\mathrm{~d}, 4 \mathrm{H}, \mathrm{Ar})$.

\section{REFERENCES AND NOTES}

1. P. G. de Gennes "The Physics of Liquid Crystals," Clarendon Press, Oxford, 1974.

2. G. W. Gray and P. A. Winsor, "Liquid Crystals and Plastic Crystals," Vol. 1 and Vol. 2, Wiley, New York, N.Y., 1974.

3. E. J. R. Sudholter, J. B. F. N. Engberts, and W. H. de Jeu, J. Phys. Chem., 86, 1908 (1982).

4. V. Busico, P. Cernicchiaro, P. Corradini, and M. Vacatello, J. Phys. Chem., 87, 1631 (1983).

5. D. C. Schroeder and J. P. Schroeder, Mol. Cryst. Liq. Cryst., 78, 221 (1981).

6. V. Busico, D. Castaldo, and M. Vacatello, Mol. Cryst. Liq. Cryst., 78, 221 (1981).

7. S. Ujiie and K. Iimura, Macromolecules, 25, 3174 (1992).

8. S. Ujiie and K. Iimura, Mol. Cryt. Liq. Cryst. Lett., 8(5), 111 (1992).

9. J. E. Proust, L. Ter-Minassian-Sarge, and E. Guyron, Solid State Commun., 11, 1227 (1972).

10. T. Uchida, M. Ohgawara, and Y. Shibata, Mol. Cryst. Liq. Cryst., 98, 149 (1983).

11. M. Ohgawara, T. Uchida, and M. Wada, Mol. Cryst. Liq. Cryst., 74, 227 (1981).

12. S. Ujiie and K. Iimura, Polym. J., 23, 1483 (1991).

13. F. Hessel and H. Finkelmann, Polym. Bull., 15, 349 (1986).

14. In the ionic sublayer, the counterions will be displaced above and below the plane of the figure to minimize repulsive interactions. 